\title{
A Review of Robots for Inspection and Maintenance of Metallic Towers of Electricity Transmission
}

\section{Una Revisión de Robots para Inspección y Mantenimiento de Torres Metálicas de Transmisión de Electricidad}

\section{Luan Meneghini}

Federal University of Santa Catarina - Florianópolis - Brazil luanmeneghini3@gmail.com

\section{André Luís Molgaro}

Federal University of Santa Catarina - Florianópolis - Brazil andremolgaro@yahoo.com.br

\section{Roberto Simoni}

Federal University of Santa Catarina - Florianópolis - Brazil roberto.simoni@ufsc.com

\section{Daniel Martins}

Federal University of Santa Catarina - Florianópolis - Brazil danielemc@gmail.com 


\begin{abstract}
Transmission towers that support electric power fines are usually inspected manually by workers that climb them and visually inspect to find oxidation points. If oxidation is seen it must be repaired to ensure the integrity of the structure. This process is slow and dangerous for the workers. Due to the possibility of electrical shocks as well as falling from the structures that are around 50 meters high. In recent years the need to substitute human workers in hostile environments by equipments and robots that bring more safety in the realization of these tasks has arisen. In this paper, a bibliographic review of papers that presented conceptions of robots that can climb transmission towers and execute its inspection, search for oxidation points and even do small maintenances is done. Through the use of a patent search methodology a preliminary and a detailed search were done, with a diversity of keywords about the subject as well as its combinations [1]. The preliminary search resulted in 2901 patents, which lead to the detailed search and finally culminated in the analysis of 164 patents, from which four showed technological potential to be analysed in this review.
\end{abstract}

Keywords: Climbing Robot, Inspection, Towers of Electricity Transmission, Maintenance.

\title{
Resumen
}

Las torres de transmisión que soportan las multas de energía eléctrica generalmente son inspeccionadas manualmente por los trabajadores que las suben e inspeccionan visualmente para encontrar puntos de oxidación. Si se observa oxidación, debe repararse para garantizar la integridad de la estructura. Este proceso es lento y peligroso para los trabajadores. Debido a la posibilidad de descargas eléctricas, así como a caídas de las estructuras que tienen alrededor de 50 metros de altura. En los últimos años, ha surgido la necesidad de sustituir trabajadores humanos en entornos hostiles por equipos y robots que brindan más seguridad en la realización de estas tareas. En este documento, se realiza una revisión bibliográfica de artículos que presentan concepciones de robots que pueden escalar torres de transmisión y ejecutar su inspección, buscar puntos de oxidación e incluso realizar pequeños mantenimientos. Mediante el uso de una metodología de búsqueda de patentes, se realizó una búsqueda preliminar y una detallada, con una diversidad de palabras clave sobre el tema y sus combinaciones [1]. La búsqueda preliminar dio como resultado 2901 patentes, lo que condujo a una búsqueda detallada y finalmente culminó en el análisis de 164 patentes, de las cuales cuatro mostraron potencial tecnológico para ser analizadas en esta revisión

Palabras claves: Robot Escalada, Inspección, Torres De Transmisión De Electricidad, Mantenimiento.

\section{INTRODUCTION}

Electricity transmission fines are characterized by transmitting energy in high voltage from a generating source to a consumer. The transmission fines are composed by cables conductors of electrical energy, towers and isolators that sustain the cables [2]. 
Brazil has around 78.8 millions consumer units [2]. In tercosof power fines, there are around 129,548 kilometers [3] that have to be operative 24 hours a day, to guarantee the qualityof the service provided.

Due to the increase of quality demanded by the consumers in the use of electricity, essentially in respect with continuityof the service provided, it is necessary to monitor constantly the condition of the towers that support the transmission lines in order to avoid any interruption in the transmission.

One of the problems encountered in the maintenance oftransmission towers is due to its oxidation. The towers are usually made of metal, and must be taken under a cautious periodic visual inspection as well as maintenances.

In accord to the normative resolution 669, from July 14, 2015, of the ANEEL (National Agency of Electrical Energy - Brazil), present in the Regulation of Minimum Maintenance Requirements, it is necessary to perform this visual inspection every 12 months.

The contribution of this review is a survey of the state of the art of cfimbing robots of the most diverse conceptions, forms of fixation, locomotion and construction. In order to show the eminent technological potential for the development of a climbing robot for inspection purposes, and that can perform small maintenances on the transmission tower structure. Robots who perform this task are not easily found on the market, and would bring many benefits, such as greater worker safety, speed on performing tasks, and would collaborate on the preventive maintenance.

\section{LITERATURE REVIEW}

A corrosion study was done in telecommunication towers. These towers are subjected to a long period of exposition to inclement weather. As a result of this, the metals utilized in the construction of these towers are likely to oxidize [4].

To evaluate the amount of corrosion in metal plates, periodically inspection is done using equipments to analyse the thickness and integrity of the plate. This is done using nondestructive tests, without causing any damage to the area analysed [5].

It is of crucial importance the realization of periodical inspections to repair surfaces of petrochemical storage tanks, or the concrete walls of dams and piers of bridges, for example. All theses structures have a high economic value, and it is essential to realize periodic inspections and repairs. Among the more relevant factors to be inspected are the rate of corrosion, potential risk of pollution, detection of leaks and cracks and so on [6].

The inspection may be very useful to avoid ecological disasters and reduce the risk for the individuals working or living around the plant or structure, however, they are usually expensive due to the necessity to use scaffolds or very dangerous since they are generally done in hostile environments [6].

As a result of this, in recent years robots began to assist humans in the realization of various types of activities, being able to replace man in high dangerousness duties.

Researchers have been focusing in designing climbing robots that can operate in vertical structures of the most various compositions. It shows the potential applicability of this kind of robot, which can replace humans in tasks that are not easily done, neither are done in a appropriately, or secure way. The application field vary from inspecting nuclear power plants to cleaning skyscrapers, welding and repairing ship hulls, and so on [7].

Climbing robots can be used to solve a series of problems in maintenance, inspection and industrial safety. The first prototypes have shown the capacity to realize tasks in hostile 
environments and inaccessible areas [5].

Industrial inspections in spheres and tanks to store petroleum, gas and derivatives are not only unhealthy to the worker, but also slow and require the utilization of sofistified equipments, which usually make the operation costly [10].

The robot can be divided in four classes depending in its construction, which are: arras and legs, wheels and trails, with threads and trails or sliding frame [8]. Regarding the mechanism of adhesion, five categories are commonly used: adhesion using suction cups and propulsion, magnetic adhesion, adhesion using gripping equipment, biomimetic adhesion, and railguided adhesion [9]. A combination of these classes and types of mechanisms can be used in different conceptions of a robot.

Robots can be used in nuclear plants to reduce human exposition not only to radiation, but also to hot places, humid and with deficient oxygenation or any other extreme condition [11].

Briones et. al developed a modular climbing robot for inspection of nuclear plants. Suction cups are used to stick the robot to walls. The robot configuration is based on two groups of four flexible pneumatic cylinders each. One group is located in the front part of the robot and the second group in the back. Three vacuum suction cups, mounted on mobile platforms, complete the robot motion. The robot can be observed in Figure 1 [11].

Pneumatic components have an excellent weightpower rate and present a natural adaptability. Almost no electric and electronic equipments are involved in pneumatic designs [11].

The maximum translation and rotation would be of $140 \mathrm{~mm}$ and 30 degree, respectively. The prototype have $10 \mathrm{~kg}$ of load capacity on wall motion and weighs $30 \mathrm{~kg}$ [11].

Analyzing the robot proposed by Briones et al. although it is a great design for power plants, it has limitations regarding adhesion and mobility on transmission towers. Power transmission towers are generally constructed of steel profiles not wide enough for the adhesion of a suction cup that provides a large load capacity, which is needed to carry the inspection and maintenance equipment. It would be necessary to have several small cups to sustain the robot, also a mechanism that allows the cups to move sideways and in the direction of the tower.
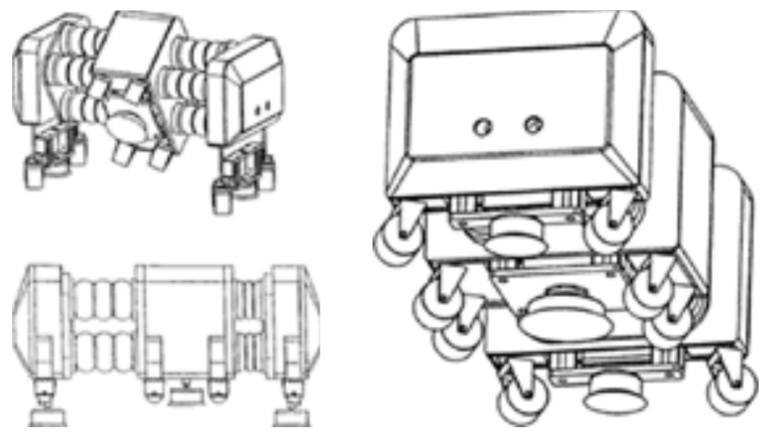

Fig. 1. Conception of the robot for inspection of nuclear power plants.

A concept presented by Huang et. al is a robot for inspection of ship hulls using magnetic adhesion. They claim that the periodical inspection of the ship hull guarantee the operational safety and prevents possible disasters in maritime environments. The main assignment of the robot is the inspection and maintenance to protect against unexpected leaks that can happen as a result of oxidation. Besides of that, the inspectors risk their lives to reach almost 
inaccessible areas of the ship [7]

The naval industry shows a great potential of application of climbing robots. Inspection of ships is an urgent challenge due to the problematic access to certain places in the ship and unhealthy conditions of work. The robot is capable to move freely inside a confined space, using a mechanism of magnetic adhesion. Figure 2 shows the robot developed [7].

The mechanical structure of the robot shown in Figure 2 has dimensions of $300 \mathrm{~mm} x$ $200 \mathrm{~mm} \times 83,54 \mathrm{~mm}$ and weighs of $10 \mathrm{~kg}$. It consists of a permanent magnetic adhesion mechanism, driving mechanism, frame of the body and inspection system. It is composed by 66 arranged permanent magnetic units. In tests the robot could overcome obstacles with certain height, which was no less than $10 \mathrm{~mm}$. Its payload capacity was nearly $6 \mathrm{~kg}$ and it had a vertical displacement rate around $7 \mathrm{~m} / \mathrm{min}$ [7]

Analyzing the design of the robot, it needs a surface wide enough to move which is not encountered in transmission towers.

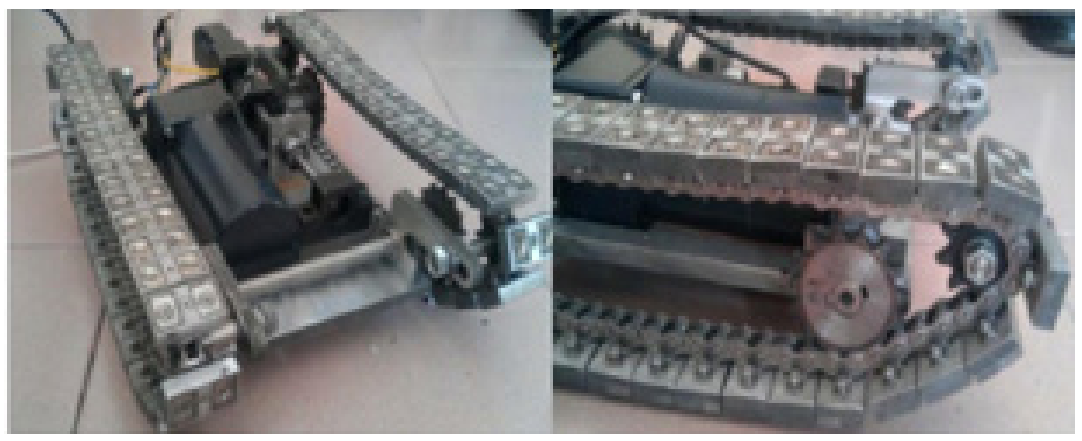

Fig. 2. Robot for inspection of ship hull.

Other concept was developed by Veiga et al. is a climbing autonomous robot to inspect metallic structures. One of the main topics of his research concerns the system of adhesion of this robot. In the present model, a system of adhesion based in magnetic wheels with active control of traction was developed, which makes the robot move carrying loads that can reach up to twice its own weight. Figure 3 shows the robot in tests [10].

The possibility of the robot lose its adhesion because of certain regions of instability in the magnetic force cannot be discarded, for example, in areas covered with a thick layer of paint. To address this problem, it is developed a safe system composed of a electromagnet, that when detects the loss of adhesion is activated, preventing the fall of the robot [10].

In relation to the locomotion system, the robot only climbs walls that are wide enough that the 4 wheels maintain equal contact, a characteristic not found in transmission towers. The extra magnet adds more safety to the design, and it doesn?t consume energy while inactive, however, the weight of this component makes the robot spend more energy to climb the tower. 


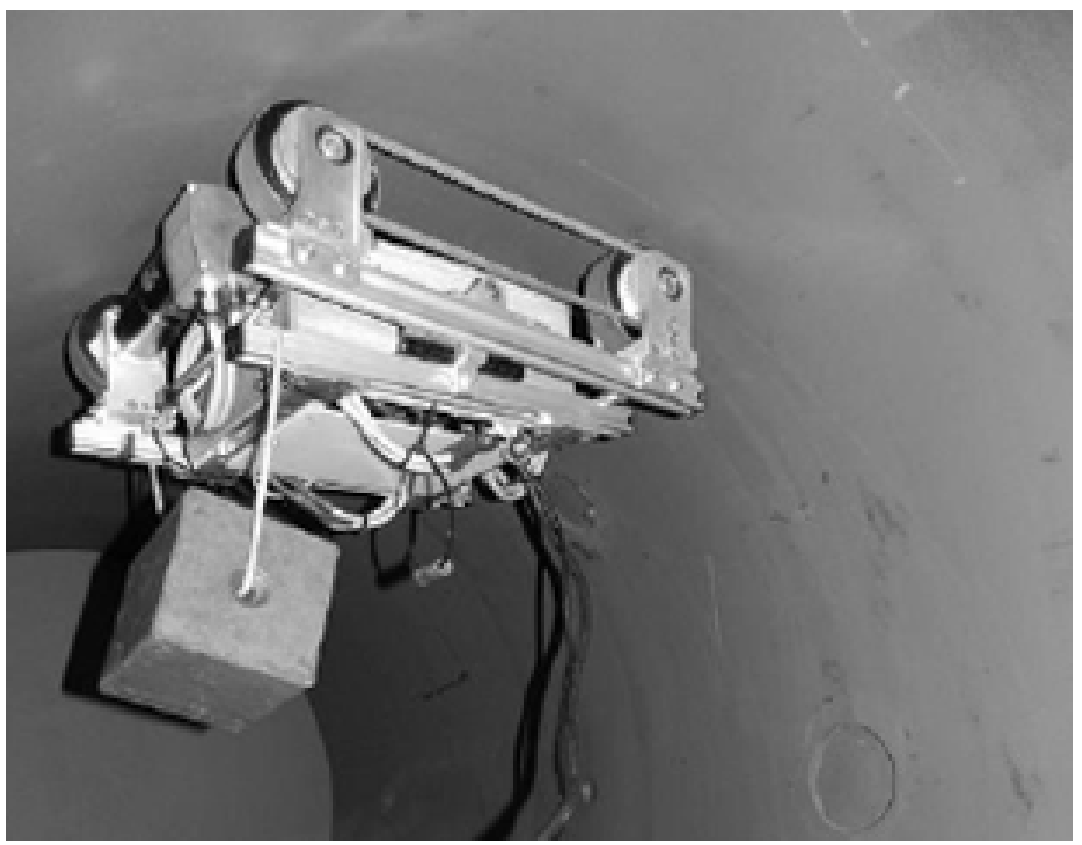

Fig. 3. Climbing Robot for metallic structures

\section{TECHONOLOGY REVIEW}

Patents are constituted by various essential informations such as priority date, inventors, depositors, drawings and claims. The priority date shows when the patent was submitted and all the rights of the patent are valid from that date onward. The inventors are the people that developed the concept. The depositors are those that have the patent rights. The International Patent Classification (IPC), is a code used to classify the patents. The descriptions as well as the drawings are utilized by the designer to expose the working principie of the idea or product [12].

The claims are the most important part of the document, considering that everything that does not appear in the claims are not protected by the patent. Hoeltgebaum presents a methodology of patent search for mechanisms. The methodology is composed by the following steps: [1]

1 - Preliminary search: this step is dedicated for the researcher to know better the subject, realizing the search with general terms;

2 - Analysis of the preliminary search: the results of the preliminary search are analysed to determine which combinations of keywords obtain better results, besides identifying the main IPCs of the field studied;

3 - Detailed search: thorough search using optimized search parameters, associating the keywords with the IPCs identified;

4 - Analysis of the detailed search: in this step less results are expected, although, with higher relevance. The designer have to filter the results analysing all the patents;

5 - Analysis of the mechanism: each patent is analysed individually, in accordance with a theoretical mechanism approach, highlighting the characteristics more important of each mechanism. 
6 - Technological mapping: in this step the designer have to classify the results using an approach more interesting to the field of study, identifying the areas well explored and promising areas.

The patent search is usually done using a database, the most accessible are the online and free databases, such as: Google Patents, Espacenet, PatentCafe, European Patent Oficce (EPO), INPI, Derwent, Free Patents Online (FPO) and others. The websites cited aboye are the most used platforms and have advanced search tools that facilitate the search. The main database used in this review was Espacenet.

It is important to establish keywords related to the subject, the combinations of these keywords for the searches provide a higher chance of success. The keywords that encompass this topic are: Robot, Mechanism, Climbing, Inspection, Tower, Magnetic.

It is worth to emphasize that the search of patents can be realized in a more advanced way in some websites, as in the case of Espacenet, which allows for example, search for keywords in either the title or in the abstract, number of patent, publication date, depositors, inventors, IPC, etc, characteristics that permit a higher precision in the search.

In the initial search more than 2901 results were found, being necessary a ?crossing of the keywords? as well as identification of the IPCs present in the results. After this it was possible to refine the search, which resulted in 164 patents that are more related with the subject addressed in this review. These results passed by an individual analysis, and then from the 164 results only four were selected. These patents are discussed in the present work.

The classifications that appeared the most during this search were B25J11/00 and B62D55/00, which are relevant to be used when looking for patents, because they can help find patents that are not easily found using the other tools. The letter B from the IPC refers to performing operations, transporting, the two IPCs shown aboye refer to hand tools, portable powerdriven tools, manipulators and land vehicles for travelling otherwise than on rails, respectively.

The patent EP1886904(A2) with title of Climbing Cleaning Robot, relates to a robot applicable for cleaning metallic surfaces such as wind tower posts. The robot has a cleaning equipment as well as cameras that allow the monitoring of its work. It is controlled remotely and has a high power electromagnetic adhesion system and also has driving wheels that perform the maneuvers necessary [13].

The invention is applicable for cleaning jobs in hazardous places, which usually are hard for workers and technicians to access, such as wind towers, ship hulls and metallic chimneys, and is comprised within the sector of remote controlled cleaning robots [13].

This cleaning robot has means to climb up a vertical or inclined metallic surface with absolute safety, and it is further provided with a high maneuvering capacity. Figure 4 shows the robot described in the patent [13].

The robot allows the cleaning of inclined or vertical surfaces. The use of magnetic wheels to move is very interesting, but the fact that it needs a surface wide enough also makes it unable to climb metallic transmission towers, but the design can be used to create some type of micro robot that does the visual inspection of the tower.

Fig. 5. Patent US2016194042(A1) 


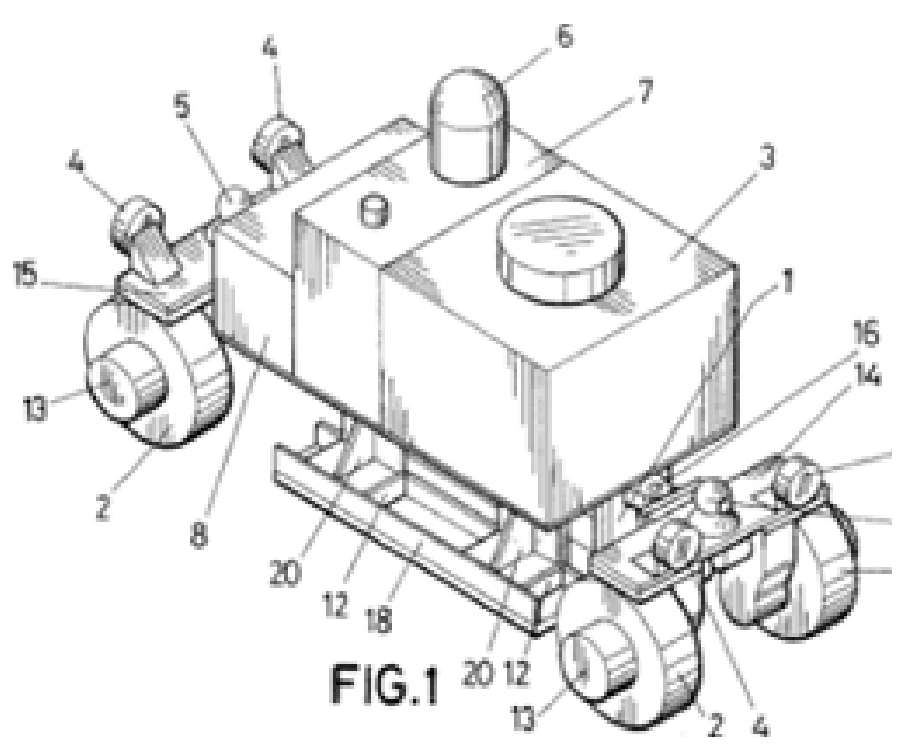

Fig. 4. Patent EP1886904(A2)

The patent US2016194042(A1) entitled Three-Wheeled Mobile Robot describes a robot configured to be versatile in its utilization due to its capacity to climb ferromagnetic surfaces, independently of its curvature. The drive system is based in three parallel wheels in a omnidirectional orientation. It has a magnetic adjustable unit. The robot is also capable to carry on a diverse number of work tasks all on ferrous surfaces. Figure 5 shows the robot [14].

This robot magnet (number 24 in Figure 5) is responsible to hold its weight against the work surface. The magnet is suspended relative to the platform so as to define a gap between a lower surface of the magnet and the work surface. Each wheel of the robot has its own motor. The central axis of the magnet is equidistant from each of the contact points of the wheels, so the motors are stressed equally during rotations.

The patent entitled Mobile Climbing Endless Track Robotic System to Perform Remote Inspections on Structures, of number US2012116583(A1), illustrated in Figure 6, is a climbing vehicle containing a suspension, transducer manipulator and surface cleaning system to perform nondestructive examination of structures while traversing the structure in all positions [15]. 


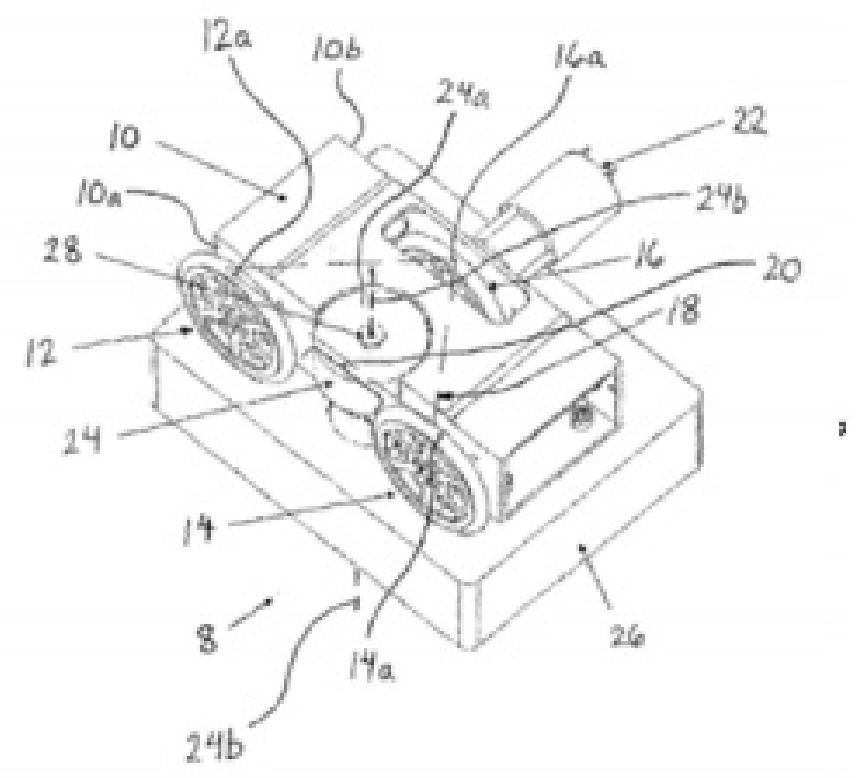

Fig. 5. Patent US2016194042(Al)

The invention is able to conform to a large range of irregularities of the climbing surfaces while maintaining contact between the track and adhering members and uniformly distributing the climbing loads on the adhering members giving the system a high payload to weight ratio [15].

This invention allows the inspection operator to control the process through a handheld controller. It also distribute the climbing forces over the adhering members (permanent magnets) on its track, similar to the invention shown in Figure 2. The inventors claim that the suspension apparatus distributes climbing loads in a way to maximize the system payload to weight ratio.

The inspection transducer that can be an ultrasonic wheel probe or a transducer in a slidable shoe is transported on a carriage, which can be attached to the robot in different directions using a universal attachment system. The carriage have one or more actuated degrees of freedom, in a way to maintain the inspection transducer aligned to the surface to be inspected. Also, a cleaning manipulator with cleaning surface tools can be attached in the same manner as the carriage to the vehicle, where the cleaning of the surface can occur at the same time of the inspection or prior to it.

The endless track is a good idea to be tested on a transmission tower after few adaptations. The degrees of freedom of the inspection transducer indeed seems to be a good solution to the problem of the robot being inclined relative to the surface inspected.

The last crucial patent is entitled Climbing Robot Movable Along a Trestle Structure, Particularly of Pole for High-Voltage Overhead Electric Lines, under the number 54 


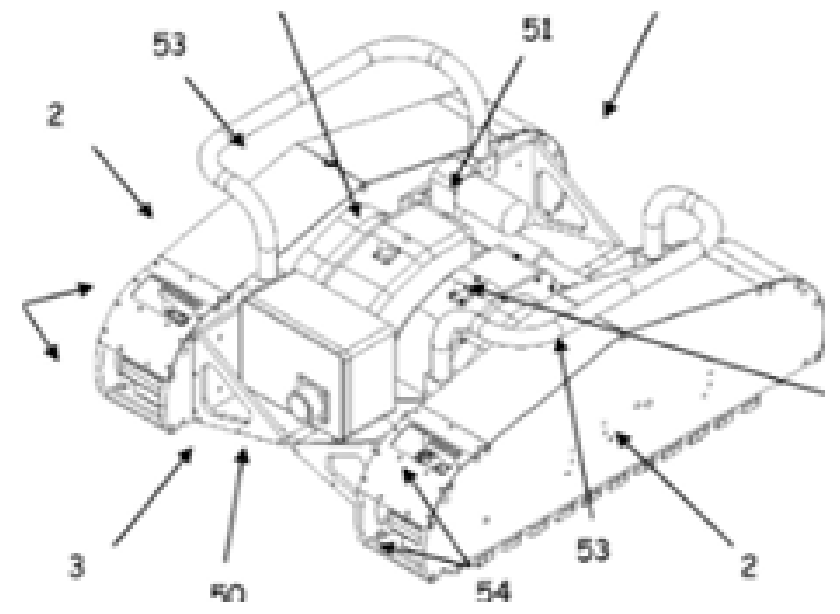

Fig. 6. Patent US2012116583(A1)

US5213172(A), shown in Figure 7, the robot is apt to climb along a trestle structure, particularly of transmission towers, and can carry work tools from the base to the top of the tower [16].

The robot includes a main support body, at least one slide movable along the body, a first gripping hand carried by the body, a second gripping hand carried by the slide, arras for moving the gripping hands substantially perpendicular to the tower. It also has a sensored position system associated with the body to acquire data of the relative position and configuration of the structure [16].
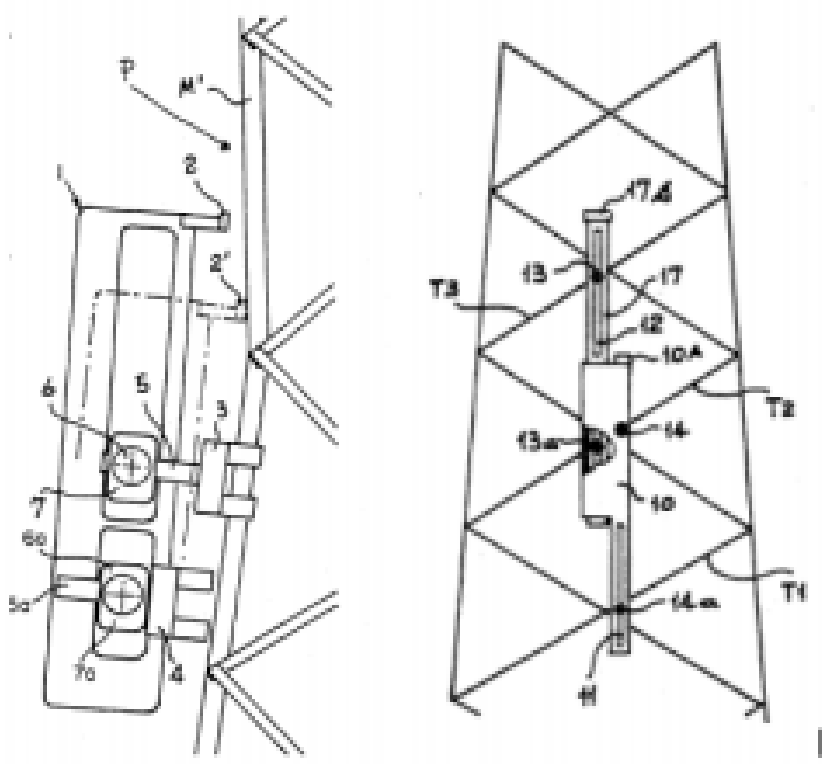

Fig. 7. Patent US5213172(A) 


\section{INNOVATION POTENTIAL}

Considering all the bibliographic search as well as the patent search realized in this paper, we can observe that exists an enormous technological potential in develop an autonomous robot that can move vertically, climbing transmission towers, performing inspections and maintenances. The increase in the substitutions of human workers in hostile and dangerous environments by autonomous robots, has increased the safety, as well as the quality of the service, and even reduced the execution time.

Analysing the main types of adhesion and locomotion systems for climbing robots, it can be stated that the transmission towers are in its majority metallic and hence the best adhesion method would be the magnetic adhesion.

It is proposed to do the mapping of the configurations of the transmission towers, more specified informations such as: dimensions, material, structural shape and position of the cables, etc, should be collected. Thus making it possible to define the trajectory of the robot for each kind of tower. As stated before Brazil has more than 129 thousand kilometers of power lines, so it would be a good idea if the robot could move autonomously from one tower to other using the cables.

Based on the review, it is possible to propose a climbing robot formed by arras with 3 degrees of freedom each with grasping system or magnetic adhesion. We believe that 4 arras are enough for the robot to be able to perform the task with agility and precision. Further simulations and tests have to be done to ensure a good performance.

The robot should be completely autonomous. With the detailed mapping of the structures of transmission limes, the robot trajectory can be programmed in a manner to facilitate its performance during the realization of the task.

Thus, it is believed that investing in this line of research can revolutionize the way many activities treated as high risk are done, contributing with this expanding market.

\section{CONCLUSIONS}

The development of mechanisms and robots that can substitute human work in hostile, unhealthy and of high risk environments has been growing, thus, improving the working conditions and safety in the realization of these tasks in such environments. The present bibliographic review is used to acknowledge the existing technologies in the field of robots that can move vertically in various types of surfaces. The use of robots to realize inspections and maintenance, and even other tasks, has presented great results.

Therefore, with the present review, it is possible to affirm that the development of a robot that can climb on transmission towers is feasible. Taking into account the reduction of inspection and maintenance time that the application of this robot would bring, and the safety it would provide in realizing the task.

Based on the patent search it was possible to notice that crossing the keywords was crucial to the success of the search. The use of advanced tools helped to find patents of more interest to the review. Also, the use of IPCs contributed in the process.

The bibliographic and technological review contributed significantly to the understanding of the subject, showing the eminent need to substitute humans in dangerous tasks by an autonomous robot that can provide more safety and agility 


\section{REFERENCES}
[1] HOELTGEBAUM,
Thiago. Variable
Compression Ratio

Engines: A Mechanism Approach. Brazil. 2016. Available: http://tede.ufsc.br/teses/ PEMC1684-D.pdf [June 21, 2017].

[2] Empresa de Pesquisa Energética (EPE), Ministério de Minas e Energia. 2016 Statistical Yearbook of electricity. 2016 Available: http://www.epe.gov.br/ AnuarioEstatisticodeEnergiaEletrica/Anu\%C3\% Alrio\%20Estat\%C3\%ADstico\%20de\%20 Energia\%20E1\%C3\%A9trica \%202016.pdf [June 7, 2017].

[3] Ministério de Minas e Energia. Boletim Mensal de Monitoramento do Sistema Elétrico Brasileiro: Fevereiro ? 2016. Available: http://www.mme.gov.br/ documents/10584/3308684/Boletim+de +Monitoramento+do+Sistema+El\%C3\%A9trico++Fevereiro-2016.pdf/a98625b1-191c-4baa-8def-1861a829dd7a [June 7, 2017].

[4] AMARAL, Cristiano Torres et al. Corrosáo em Estruturas Metálicas: Uma Breve Discussáo Acerca da Prevengáo em Torres de Telecomunicagáo. Brasil. 2008. Available http://revistas2.unibh.br/index.php/dcet/article/view/211 [June 7, 2017].

[5] LA ROSA, Guido et al. A low-cost lightweight climbing robot for the inspection of vertical surfaces. Italy. 2002. Available http://www.sciencedirect.com/science/article/pfi/ S0957415800000465 [June 7, 2017].

[6] LONGO, Domenico. MUSCATO, Giovanni. The Alicia Climbing Robot: A Three-Module Robot for

Automatic Wall Inspection. March, 2016. Available

http://ieeexplore.iee.org/stamp/stamp.jsp?arnumber=1598052 [June

7, 2017].

[7] HUANG,Haocai et al. Design and mperformance analysis of a tracked wall-climbing robot for ship inspection in shipbuilding. China. 2017. Available

http://www.sciencedirect.com/science/article/pfi/S0029801817300033 [June 7, 2017].

[8] LYNCH, G.A., Clark, J.E., Lin, P.C., Koditschek, D.E., 2012. A bioinspired dynamical vertical climbing robot. Int. J. Robot. Res. 31 (8), 974?996.

[9] SHEN, W., Gu J., Shen, Y., 2005. Proposed wall climbing robot with permanent magnetic tracks for inspecting oil tanks. In: Proceedings of the IEEE International Conference on Mechatronics and Automation, vol. 4, pp. 2072?2077.

[10] VEIGA, Ricardo S. et al. Controlador Fuzzy para um Eletroíma de Apoio á Adesáo Magnética de um Robó Escalador. Brasil. 2014. Available http://www.eletrica.ufpr.br/ anais/cba/2014/PDF/1569934083.pdf

[June 7, 2017].

[11] BRIONES, Leoncio et al. Wall-Climbing Robot for Inspection in Nuclear Power Plants. EUA. 1994. Available http://ieeexploredeee.org/abstract/document/351292/ [June 7, 2017]. 
[12] MALETZ, Ellas Rená, BARRETO, Rodrigo Luís Pereira, MARTINS, Daniel. Revisáo do Estado da Arte de Camas Hospitalares: Análise de Mercado e Pesquisa de Patentes. 2016.

[13] PEREZ, Moure Manuel. Climbing cleaning robot. 2008. EP1886904A2.

[14] KEITH, Schlee. Three-WheeledMobile Robot. 2016.

US2016194042A1.

[15] JAMES, Beard; STEPHEN, Canfield; STEVE, Glovsky. Mobile, climbing endless track robotic system to perform remote inspections on structures. 2012. US2012116583A1.

[16] PARIS, Luigi.Climbing robot, movable along a trestle structure, particularly of pole for high-voltage overhead electric fines. United States. 1990. US5213172 (A). 